\title{
Richard S. Stein to Receive 1999 Von Hippel Award for Contributions to the Science of Polymers
}

The Materials Research Society's highest honor, the Von Hippel Award, this year will be given to Richard S. Stein of the University of Massachusetts-Amherst in "recognition of his seminal work in the development of rheo-optical techniques for polymer characterization and property assessment, his profound contributions leading to a fundamental understanding of how polymeric materials respond to deformation in the melt and solid states, and his pioneering role in the development of graduate education in polymer materials." The Von Hippel Award is given annually to an individual in recognition of outstanding contributions to interdisciplinary research on materials.

Stein has dedicated about 50 years of research on how polymer materials orient, crystallize, and deform. He originated the field of rheo-optics which encompasses simultaneous real-time measurement of optical properties and polymer melt rheology. Through the rheo-optical approach, Stein used various optical techniques, including both small angle neutron x-ray scattering and light scattering, wide-angle $x$-ray diffraction, birefringence, and infrared dichroism. He used these optical methods to probe the spatial and orientational ordering in semicrystalline polymers and polymer blends, and particularly the changes in the structure under anelastic and plastic deformation.

During his college days, from undergraduate to postdoctoral studies, Stein constructed one of the first apparatus for the study of the angular dependence of light scattering from a polymer solution and made one of the first measurements of the radius of gyration of a polymer molecule (cellulose acetate). He demonstrated how to combine measurements of birefringence and $x$-ray diffraction to obtain quantitative measurements on the orientation of the crystalline and of the amorphous regions of polyethylene. He designed and constructed one of the first $x$-ray diffractometers capable of in situ polymer information studies. He showed the effect of the crystalline field in causing splitting of the infrared bands of polyethylene crystals and demonstrated how these could be used to determine both the degree of crystallinity and a quantitative measurement of the extent of molecular and crystal orientation.

His methods are now widely used in industrial and academic laboratories, plus many of the principles and methods he developed are now applied to the interdisciplinary field of complex fluids. His light

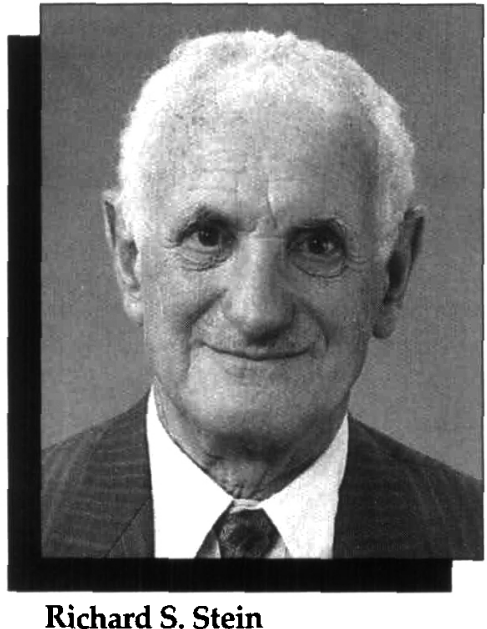

Department. He has advised over $140 \mathrm{PhD}$ and postdoctoral students. He has held numerous visiting professorships including Syracuse University, Laval University in Quebec, Ecole Superior Physics and Chemistry of the City of Paris, University of Akron, the Universities of Ulm and Hamburg, Cambridge University, and the United Arab Emirates University.

Stein has made a great impact on the Society of Polymer Science in Japan where he collaborated with several research groups. He gave a series of lectures on polymer physics; rheooptics; and relationships between polymer orientation, deformation, and mechanical properties in many Japanese universities and research institutes in industries. In 1988, Japan recognized his efforts with the Society of Polymer Science Japan Award for Distinguished Service in the Advancement of Polymer Science.

In the United States, Stein was appointed in 1994 as the chair of a National Research Council (NRC) committee to conduct a study on the future of polymer science and engineering. The subsequent account, known as the "Stein Report," overviews the important role polymeric materials have on society and the numerous outstanding scientific and technological challenges and opportunities in this interdisciplinary area of materials research. Stein continues to be heavily involved in public affairs of the National Academy of Engineering (NAE) and the National Academy of Science (NAS) and is assisting with a project on the use of polymers in biomedical applications with a feature video in the NRC series on "Beyond Discovery." His features illustrate how basic research in implantable, biodegradable polymers used in drug therapy leads to applications such as drug delivery systems that enable precise placement of medication to treat cancer.

Stein received an MA and PhD degree in physical chemistry from Princeton University, and has been with the University of Massachusetts since 1950 . He has published over 400 papers and received numerous awards. He is a member of the NAS and NAE, and he was elected to the Plastic Hall of Fame in 1993.

Following his acceptance of the Von Hippel Award during the Award Ceremony on Wednesday, December 1, at 6:00 p.m. in Salon E of the Boston Marriott Hotel at the 1999 MRS Fall Meeting, Stein will present his talk, "Studies of Polymers with Radiation." 